\title{
CONTEÚDOS CURRICULARES EM CIÊNCIAS NATURAIS PARA O PLANEJAMENTO DE ENSINO E O DESENVOLVIMENTO DE HABILIDADES EM LÍNGUA PORTUGUESA NOS ANOS INICIAIS
}

\author{
CURRICULUM CONTENTS IN NATURAL SCIENCES FOR TEACHING \\ PLANNING AND THE DEVELOPMENT OF PORTUGUESE LANGUAGE SKILLS IN \\ THE EARLY YEARS
}

DOI: http://dx.doi.org/10.23926/RPD.2526-2149.2018.v3.n2.p700-719.id290

\author{
Meg de Messias \\ Drobinichi Nunes \\ Graduada em Pedagogia \\ (UNESP). \\ megdrobinichi@gmail.com
}

\author{
Jair Lopes Junior \\ Doutor em Psicologia \\ Experimental (USP). \\ Professor pela Universidade \\ Estadual Paulista (UNESP). \\ jair.lopes-junior@unesp.br
}

\author{
Vera Lucia Messias \\ Fialho Capellini \\ Doutora em Educação \\ Especial (UFSCar). \\ Professora pela Universidade \\ Estadual Paulista (UNESP). \\ vera.capellini@unesp.br
}

\begin{abstract}
Resumo: Neste artigo apresentamos uma proposta em Ciências Naturais realizada durante o segundo semestre letivo do ano de 2017 em uma escola da rede pública de São Paulo em um município do interior do Estado. Esta proposta foi realizada no intuito de aproximar o conteúdo científico do cotidiano de alunos matriculados em um $5^{\circ}$ ano do Ensino Fundamental para investigar a hipótese de influências geradas por tal aproximação no desenvolvimento de habilidades em língua portuguesa. Para tanto, foram estabelecidas relações entre o uso desta proposta e o processo de alfabetização científica (AC) na perspectiva de ciência-tecnologiasociedade-ambiente (CTSA). A análise desta intervenção efetuou-se por indicadores que pudessem demonstrar se a alfabetização científica estaria ocorrendo, bem como na observação do processo de produção textual guiada por bilhetes orientadores. Os resultados demonstraram a possibilidade de articulação entre às duas disciplinas através do planejamento didático considerando o uso de gêneros textuais. As conclusões deste estudo revelam que o planejamento de ensino interdisciplinar através do uso dos gêneros textuais oferece sentido às ciências em suas práticas sociais, assim como, a presença de indicadores de AC como resultado das intervenções feitas pela pesquisa evidencia um estimulo para demonstração de habilidades em ambas disciplinas.

Palavras-chave: Ensino de ciências. CTSA. Habilidades em língua portuguesa. Alfabetização científica.
\end{abstract}

\begin{abstract}
In this article we present an educational proposal in Natural Sciences carried out during the second semester of 2017 in a public school located in the interior of São Paulo state. This proposal aimed to approach the scientific content of students daily life which were enrolled in a 5th grade of Elementary School in order to investigate the hypothesis of influences generated by this proximity to the development of Portuguese language skills. Therefore, relations between the use of this proposal and the scientific literacy (SL) process from the science-technology-societyenvironment(STSE) perspective were established. The analysis of this intervention was made by indicators that could demonstrate if scientific literacy was occurring, as well as the observation of the textual production process guided by guiding tickets (notes). The results demonstrated the possibility of articulation between the two disciplines through a didactic planning considering the use of textual genres. The conclusions of this study reveal that planning interdisciplinary teaching using different textual genres makes sense to the sciences in their social practices, as well as the presence of SL indicators as a result of the interventions made by the research shows motivation for demonstrating skills in both disciplines.
\end{abstract}

Keywords: Science teaching. STSE. Portuguese language skills. Scientific Literacy. 


\title{
1 INTRODUÇÃO
}

Os Parâmetros Curriculares Nacionais (PCNs) firmam a necessidade de superação às práticas pedagógicas tradicionais, enraizadas na memorização e fragmentação dos conhecimentos, defendendo assim uma proposta de ensino de ciências contextualizada e interdisciplinar.

\begin{abstract}
Desde o início do processo de escolarização e alfabetização, os temas de natureza científica e técnica, por sua presença variada, podem ser de grande ajuda, por permitirem diferentes formas de expressão. Não se trata somente de ensinar a ler e escrever para que os alunos possam aprender Ciências, mas também de fazer usos das Ciências para que os alunos possam aprender a ler e a escrever (BRASIL, 1997, p. 62).
\end{abstract}

Desse modo, a abordagem em ciências quando articulada ao processo de aquisição da língua materna pode contribuir consideravelmente para que as atividades escolares estejam melhores contextualizadas, fazendo-as mais significativas para os alunos.

Quanto aos anos iniciais do ensino fundamental, consideramos que o ensino de ciências pode estimular o aluno a construir significados sobre o mundo por meio de processos de reflexão, numa expansão significativa dos seus conhecimentos e cultura, o que lhe possibilita uma participação efetiva em sociedade (CHASSOT, 2003; SANTOS, 2007). Logo, discutir o conhecimento e as suas relações com a sociedade, ciência e tecnologia possibilita a superação da fragmentação do ensino e contribui para um novo ponto de vista curricular articulando entre si diversos conhecimentos.

Acerca deste aspecto, Demo (2001) claramente advoga que dentre os desafios impostos pelo avanço da interdisciplinaridade, apresenta-se como imperativa a comunicação entre as Ciências e, cumpre reconhecer, que conceitos aparentemente comuns mostram-se presentes em distintas áreas do conhecimento, com semânticas particulares, mas também contribuindo para entendimentos mais ampliados. Tal condição impõe a necessidade da atenção permanente do professor na identificação e na explicitação destas articulações conceituais.

Em conformidade com a perspectiva interdisciplinar da área de ciências naturais, o presente estudo investigou estratégias metodológicas que poderiam viabilizar a aquisição de habilidades recomendadas em língua portuguesa nos anos iniciais em articulação curricular com ciências da natureza.

Em acréscimo, pretende-se igualmente ampliar lastros de produção científica consistentes com a interdisciplinaridade entre ciências naturais e língua portuguesa demonstrado pela afirmação levantada por Lorenzetti; Delizoicov (2001) num estudo, em que 
defendem o princípio de que a alfabetização científica pode e deve ser desenvolvida desde o início do processo de escolarização, mesmo antes que o aluno saiba ler e escrever.

Com base nesse princípio defendido por esses autores, emerge a hipótese investigada, segundo a qual, sob adequadas condições metodológicas, as ciências naturais podem auxiliar no processo de desenvolvimento da leitura e da escrita no decorrer do ensino fundamental, bem como se formar num aperfeiçoador, visto que contribui para atribuição de sentido à estas.

\section{REFERENCIAL TEÓRICO}

A sociedade em sua dinamização abrangendo as áreas de ciência e tecnologia fomenta uma formação aos mais jovens nesse mesmo viés, proporcionando a compreensão e a aquisição de capacidades que os permitam agir nesse meio. A educação deve subsidiar situações aos alunos, assim como oportunizar o desenvolvimento de atitudes de investigação, de raciocínio, de tomada de decisões, argumentação, análise e compreensão de situações-problemas.

Observa-se que na prática referente à escola, o ensino de ciências naturais sofre com a priorização de disciplinas como português e matemática (VIECHENESKI; CARLETTO, 2010), podendo em sua abordagem conter informações desvinculadas de conhecimentos significativos e de aplicabilidade no cotidiano. Essa priorização de outros conhecimentos em relação à ciências, consequentemente, age sobre a aprendizagem com a construção de conceitos equivocados no entendimento do "fazer ciência" pelos alunos, ancorando-se em visões empiristas, indutivistas e dogmáticas sobre ciência.

Para se ter um posicionamento crítico frente aos temas discutidos em sala de aula, é fundamental que o aluno conquiste o conhecimento científico como instrumento de análise da sua realidade, assim como das situações problema em que se depara. Assim, é importante que se aprenda ciências de maneira a questionar e problematizar o meio, haja vista a necessidade da avaliação crítica de informações veiculadas pela mídia, em virtude de:

Aumentar o nível de entendimento público da Ciência é hoje uma necessidade, não só como um prazer intelectual, mas também como uma necessidade de sobrevivência do homem. É uma necessidade cultural ampliar o universo de conhecimentos científicos, tendo em vista que hoje se convive mais intensamente com a Ciência, a Tecnologia e seus artefatos. (LORENZETTI; DELIZOICOV, 2001, p. 5).

Com isso, pode ocorrer um debate e a proposição de soluções, auxiliando aos alunos a reconhecerem que o conhecimento científico é uma construção social. Além do mais, que o mesmo não é um conhecimento determinado e estritamente relacionado aos cientistas, como é divulgado em meios de divulgação não-científica e na mídia em geral. Entretanto, é importante favorecer ao aluno a compreensão de que esse é um conhecimento em constante construção e 
reconstrução, podendo ser questionado, modificado e melhorado de acordo com novas elaborações.

Desta maneira, a aprendizagem em ciências pode ser significativa e contribuir para a criticidade fornecendo aos alunos e aos professores oportunidades de realizar atividades que lhes permitam desenvolver o pensamento, a função planejadora da linguagem, a fala e a escrita como ferramentas de ponderação, criação, registro, comunicação, interação social para, consequentemente, obter-se a aprendizagem.

Para tanto, entre as competências e habilidades que podem subsidiar um aluno a se tornar um cidadão crítico, destaca-se a competência leitora, definida pelas Orientações Curriculares do Estado de São Paulo para os Anos Iniciais (2013) como a capacidade que a criança tem de compreender, utilizar e analisar textos em diversas linguagens. Destaca-se que o letramento também advém sobre conteúdos específicos das disciplinas escolares, excedendo a área da linguagem, incluindo assim saberes científicos. Os conteúdos científicos podem auxiliar no desenvolvimento de competências, no pensar e fazer ciência a partir de habilidades específicas como observação e identificação, levantamento de hipóteses, registro e análise de dados, comunicação, descrição, argumentação e explicação de conclusões.

Sob essa ótica, consequentemente, acreditamos que o ensino de ciências se institui como um aliado para o desenvolvimento da leitura e da escrita ao longo do ensino fundamental. De acordo com Lorenzetti; Delizoicov (2001, p. 3) a definição de alfabetizar cientificamente seria a "capacidade de o indivíduo ler, compreender e expressar opinião sobre assuntos que envolvam a ciência."

Assim, a alfabetização científica é considerada como um conceito amplo que abrange conhecimento, noção, saber, instrução e informação incluindo descrições, hipóteses, conceitos, princípios e procedimento dos fazeres cotidianos da ciência, da linguagem científica e da decodificação das crenças aderidas a ela (CHASSOT, 2003).

Ao considerar a ciência como linguagem a fim de descomplexificar a observação do mundo (natural) e compreendê-la como descrição dos fenômenos que nele ocorrem, podemos nos perceber no meio em que estamos inseridos. Ainda, para Chassot (2003) a elaboração dessa explicação do mundo natural é o conceito de fazer ciência, isto é, o descrever a natureza numa linguagem científica; consequentemente, oportunizar o entendimento ou a leitura dessa linguagem é o alfabetizar cientificamente.

Oferecer a alfabetização científica como almejo da inclusão social, onde a ciência deixa de ser meramente entendida, significa "ampliar a possibilidade de pensar a ciência como uma 
linguagem para entendermos o mundo natural" (SASSERON; CARVALHO, 2008, p. 94). Aqui, a alfabetização científica assume-se como um conjunto de conhecimentos que facilita aos indivíduos a leitura do mundo em que vivem.

Portanto, é insuficiente que a escola favoreça exclusivamente o letramento em favor da letra (propriamente dita) e dos gêneros discursivos escritos e impressos. É imprescindível o foco na realização dos multiletramentos que circulam fora da escola, sendo esses, a maior parte dos gêneros discursivos que estão presentes nas atividades letradas, nas mídias em geral. Sendo assim, é fundamental compreender que a capacidade de leitura e escrita, da concepção de letramento a respeito da linguagem não subsidia mais, essencialmente, a vida contemporânea vista inclusão tecnológica/ digital e científica.

O enfoque CTSA permite a realização de uma educação problematizadora, reflexiva inserida nas discussões presentes nos PCNs. Entretanto, pouco é refletido sobre um modo de realizar essa perspectiva na escola de anos iniciais. Esse enfoque tem por objetivo a problematização de temáticas que assegurem o comprometimento social dos alunos e o processo de educação cidadã. A inserção dessa abordagem nos anos iniciais numa perspectiva crítica (SANTOS, 2007) é aumentar a reflexão sobre dinamizações da sociedade no contexto atual, incluindo em aula discussões sobre questões econômicas, políticas, sociais, culturais, éticas e ambientais. Discussões essas, no entanto, que precisam de entendimentos conceituais a respeito de temas e conteúdos ligados aos aspectos sócio-científicos (ASC), no qual costumam ser assuntos discutíveis, cotidianos, e interdisciplinares pela sua natureza real.

Com isso, emerge o trabalho com os (multi)letramentos, com base nos discursos de divulgação da ciência, que são melhor abordados nas disciplinas específicas. Isso não representa dificuldades de conciliação, visto que o pedagogo não é formado para uma única disciplina e que sua atuação é polivalente. Portanto, ensinar ciência implica, ensinar a ler sua linguagem, incluindo sua estrutura sintática, discursiva e vocabulário, interpretando também esquemas, gráficos e tabelas.

Portanto, o ensino nessa área deve ajudar o aluno a elaborar um argumento científico. Tal elaboração, por seu turno, envolveria o desenvolvimento de habilidades constituintes, ou seja, que definem a emissão de um argumento científico. Dentre tais habilidades caberia destacar, em consenso com Morais; Andrade (2009) ações que definem a leitura compreensiva da linguagem da ciência. Esta leitura impõe habilidades de discriminação dos conteúdos relevantes, da vinculação semântica entre, de um lado, realidades vivenciadas e conhecidas e, de outro, o conteúdo textual. Contudo, de igual relevância, impõe-se o ensino intencionalmente 
direcionado ao desenvolvimento das habilidades definidas pela questionamento da confiabilidade das fontes consultadas e pelos posicionamentos que, em última instância, materializem as necessárias reflexões do aluno sobre o tema e os materiais em questão.

Assim, o desenvolvimento das competências leitora e escritora é responsabilidade de todas áreas escolares. Compete as disciplinas oferecer auxílio aos alunos para construir essas competências, a fim de ler e escrever gêneros textuais. Isto é, pode-se referenciar a um modo de ler e escrever próprio da área de ciências, que contribui na construção de conhecimentos, competências e habilidades por ela requeridas.

Consequentemente, a escola é o lugar em que o aluno exerce os primeiros contatos com a ciência de maneira sistemática e, também onde tem a sua inserção na cultura científica, processo esse, importante no ensino de ciências. Efetivamente na prática o processo de aquisição da linguagem científica, com base nas aquisições diárias acerca do conhecimento escolar, seja em oralidade ou escrita, ocorre principalmente no uso sistematizado do relato de experiências; da explicação de causas e consequências de ações obtidas por meio delas; de representação das relações entre os seres vivos, sejam elas, através da expressão por palavras, desenhos, recortes e colagem.

Logo, enfatizamos a necessidade de estabelecer relação entre os conteúdos e o cotidiano, favorecendo o exercício de uma linguagem relacionada à aprendizagem do conhecimento científico na disciplina de ciências naturais.

\section{Metodologia}

O presente estudo consiste em uma pesquisa de caráter descritivo, abordando um procedimento de ensino realizado em sala de aula de uma escola da rede pública, localizada na periferia de uma cidade do interior do Estado de São Paulo. A pesquisa foi executada com alunos de uma turma de $5^{\circ}$ ano na faixa etária entre 10 e 11 anos, considerando a organização curricular para escolas públicas do Estado de São Paulo, presente na Matriz de Referência para a Avaliação Processual (SÃO PAULO, 2016).

No período do ano letivo destinado para as habilidades salientadas, os alunos teriam tido contato com os gêneros textuais escolhidos (divulgação científica; carta de leitor). Assim sendo, admite-se que a pesquisa se configuraria em uma efetiva contribuição para aprendizagem dos mesmos, pois no segundo semestre do ano é previsto por essa matriz paulista que os alunos acompanhem novamente o texto de divulgação científica, verbete e carta de leitor. 
A seguir, exporemos os procedimentos metodológicos utilizados para a obtenção dos resultados desta pesquisa, tal como o percurso que subsidiou a aplicação, elaboração e a organização das aulas quanto aos conteúdos abordados de ciências naturais, que acarretaram numa produção textual.

Como já referido, a proposição do estudo consistiu na análise da relação entre os conteúdos da disciplina de ciências naturais e o desenvolvimento de habilidades em língua portuguesa previstas no currículo pela Matriz de Referência para a Avaliação Processual (SÃO PAULO, 2016). Este documento, trata-se de um guia para a aplicação das Avaliações de Aprendizagem em Processo (AAP) nas escolas públicas estaduais do Estado de São Paulo.

Para a realização da produção textual adotamos a abordagem processual da escrita por meio da metodologia de bilhetes orientadores (FUZER, 2012). Assim, realizaram-se atividades de leitura, produção do texto, avaliação e reescrita pelos alunos. Essa proposta de produção textual envolveu o gênero carta de leitor, verbete e divulgação científica.

Salientamos, que a pesquisa não intentou unicamente avaliar os descritores de habilidades com base em indicadores do processo de $\mathrm{AC}$, pois acreditamos que o desenvolvimento dessas consiste em situações contínuas. Desse modo, especificamos que o estudo pretendeu por contribuir com o desenvolvimento de habilidades em língua portuguesa, visto que as mesmas faziam parte de uma proposta curricular que as professoras do quinto ano já estavam seguindo.

Abaixo apresentamos os instrumentos, perspectivas teóricas, metodológicas que subsidiaram o planejamento e a análise da intervenção e dos resultados alcançados.

\subsection{INDICADORES DE ALFABETIZAÇÃO CIENTÍFICA (AC)}

Para o alcance da AC é necessário perceber indicativos do processo nos alunos, ou seja, medir o grau em que esses alunos se encontram. Sasseron; Carvalho (2008, p. 337-338) dizem que é possível encontrar "alguns indicadores de que estas habilidades estão sendo trabalhadas e desenvolvidas entre os alunos, ou seja, alguns indicadores da alfabetização científica.”

Destaca-se que esses indicadores são definidos por ações e habilidades que são desempenhadas pelos alunos durante a resolução de um problema, ou seja, seriam competências mútuas desenvolvidas e utilizadas para a resolução e discussão de um problema numa procura por relações quanto ao problema e as elaborações mentais dos alunos. O Quadro 1 apresenta os indicadores de AC como subsídio para análise dos resultados dessa pesquisa. 
Quadro 1 - indicadores de alfabetização científica

\begin{tabular}{|c|c|}
\hline Sasseron; Carvalho (2008) & Pizarro; Lopes Júnior (2015) \\
\hline Seriação de Informações & \\
Organização de Informações & Articular Ideias \\
Classificação de Informações & Investigar \\
Raciocínio Lógico & Argumentar \\
Raciocínio Proporcional & Ler em Ciências \\
Levantamento de Hipóteses & Escrever em Ciências \\
Teste de Hipóteses & \\
Justificativa & \\
Previsão & \\
Explicação &
\end{tabular}

Fonte: Sasseron e Carvalho (2008) e Pizarro e Lopes Júnior (2015).

\subsection{O BILHETE ORIENTADOR COMO INSTRUMENTO INTERATIVO DE PRODUÇÃO TEXTUAL}

Alguns estudos (PETRONILO, 2007; COSTA; FUZER, 2011; FUZER, 2012) alegam que um dos aspectos relevantes para as dificuldades dos alunos com textos é a falta de motivação, visto que não há propósito efetivo para a significação e utilização dos textos produzidos por eles. Essa perspectiva está presente em todo o processo de produção textual, contudo, concretiza-se no período de pós-escrita posto por Soares (2009 apud FUZER, 2012) que envolve atividades como um:

[...] período de leitura e avaliação do que foi escrito e o recebimento de feedback do professor ou outros leitores sobre o conteúdo do texto para que o autor possa melhorálo e, por conseguinte, encaminhar o produto final para sua finalidade no meio social" (FUZER, 2012, p. 216).

Durante esse processo de escrita e reescrita de textos o professor exerce quatro papéis, conforme a etapa de produção dos alunos. Um dos papéis é o de leitor, expressando sua opinião sobre o escrito. Por conseguinte, o professor ajuda a melhorar a produção textual, no intuito de qualificar o texto em produção para um objetivo, apontando percursos mediante a práticas relacionadas ao gênero, assim, exercendo o papel de assistente. Com isso, na ocasião em que a preocupação em melhorar os textos do aluno, por meio de comentários estiver encerrada, o professor exercerá o papel de avaliador. Em última instância, exerce a função de examinador, apresentando uma avaliação das qualidades observadas.

Portanto, o texto e o contexto estão sempre relacionados segundo essa visão, de maneira que o texto mostra as influências do contexto em que é produzido, da mesma maneira que as variáveis do contexto atuam sobre a sua configuração linguística. O bilhete orientador, dessa forma, oportuniza esse processo e pode ser um instrumento auxiliador do desenvolvimento da escrita. 


\subsection{A SEQUÊNCIA DIDÁTICA (SD)}

No que concerne às etapas constituintes à elaboração da sequência didática que se dá nesta pesquisa, têm-se dois momentos, o primeiro, destinado aos conteúdos de ciências, combinado com o ensino por CTSA e alfabetização científica; e, quanto ao ensino do gênero textual carta de leitor, há a proposta de conciliação metodológica entre a proposição do bilhete orientador por Fuzer (2012) norteando os escritos e a concepção mais conhecida na área da Linguagem, tendo base teórica o Interacionismo Sócio Discursivo (ISD) proposto por Bronckart (2003) que, consequentemente, se ancora em trabalhos de autores como Vygotsky e Bakhtin.

Nesta linha teórica, o conceito de sequência didática é tido como um conjunto de atividades escolares que estão sistematizadas acerca de um gênero textual que pode ser oral ou escrito (SCHNEUWLY; DOLZ, 2004). A estrutura de construção da SD nesse seguimento deve partir dos passos a) apresentação da situação, definição e formulação da tarefa; b) produção inicial que estabelece o primeiro contato entre o aluno e o gênero textual; c) módulos de atividade que são atividades preparadas pelo professor de observação e análise do gênero; d) produção final, destinado à prática de elaboração textual.

As adaptações referidas neste estudo dizem respeito à inserção do bilhete orientador (FUZER, 2012) na ocasião da realização dos módulos do modelo da SD. Como já descrito, durante esse processo de escrita e reescrita de textos, o professor desempenha quatro papéis diferentes (leitor, assistente, avaliador e examinador). Unimos essas duas propostas metodológicas correspondendo-as, então as etapas de pré-escrita à apresentação da situação (as atividades e conteúdos em ciências, bem como a análise do gênero textual de divulgação científica); escrita do texto à prática inicial (diagnóstico dos conhecimentos prévios através da escrita do gênero carta ao leitor em resposta ao texto de divulgação científica); revisão (resposta e reescrita com orientação dos bilhetes) aos módulos (atividades sistemáticas para aprender as características do gênero carta de leitor) e, por fim a versão final do texto (professor exerce o papel de examinador) à produção final. Com isso, apresentamos também abaixo o cronograma das atividades realizadas na escola, com vistas a sintetizar o desenvolvimento de cada etapa. 
Quadro 2 - organização da aplicação da sequência didática

\begin{tabular}{|c|c|}
\hline AULAS & ATIVIDADES PREVISTAS \\
\hline \multicolumn{2}{|c|}{$\begin{array}{l}\text { Etapa } 1 \text { - Apresentação da Situação (SCHNEUWLY; DOLZ, 2004) ou Pré-escrita (SOARES, } \\
2009 \text { apud COSTA; FUZER, 2011) }\end{array}$} \\
\hline AULA 1 & $\begin{array}{l}\text { Exploração do Sistema Solar (conforme as expectativas de } \\
\text { Aprendizagem previstas nas Orientações Curriculares Estado de São } \\
\text { Paulo para os Ano Iniciais); Conteúdos Abrangidos: distância dos } \\
\text { planetas; temperatura; localização, entre outras características. }\end{array}$ \\
\hline AULA 2 & $\begin{array}{l}\text { Exploração do Sistema Solar a partir de história da ciência } \\
\text { (astronomia) e suas implicações cotidianas; Expansão pesquisa e } \\
\text { exploração espacial; Diferenciação entre sondas, foguetes entre outros; } \\
\text { Problematização do lixo espacial e implicações (tema gerador). }\end{array}$ \\
\hline AULA 3 & Texto Expositivo de Divulgação Científica (Tipologia e Finalidade) \\
\hline \multicolumn{2}{|c|}{$\begin{array}{c}\text { Etapa } 2 \text { - Produção Inicial (SCHNEUWLY; DOLZ, 2004) ou Escrita (SOARES, } 2009 \text { apud } \\
\text { COSTA; FUZER, 2011) }\end{array}$} \\
\hline AULA 4 & $\begin{array}{l}\text { Produção Inicial da carta de leitor (duplas) com base no gênero textual } \\
\text { de divulgação científica de tema "lixo espacial." }\end{array}$ \\
\hline \multicolumn{2}{|r|}{ Etapa 3 - Módulo 1 (SCHNEUWLY; DOLZ, 2004) } \\
\hline AULA 5 & $\begin{array}{c}\text { Carta de Leitor (Tipologia); } 1^{\circ} \text { Bilhete Orientador (FUZER, 2012) em } \\
\text { resposta à Produção Inicial sem intervenção (Papel de Leitor); } \\
\text { Reescrita da carta de leitor pelos alunos. }\end{array}$ \\
\hline \multicolumn{2}{|r|}{ Etapa 4 - Módulo 2 (SCHNEUWLY; DOLZ, 2004) } \\
\hline AULA 6 & $\begin{array}{l}\text { Carta de Leitor (Finalidade); } 2^{\circ} \text { Bilhete Orientador (FUZER, 2012) } \\
\text { (Papel de Assistente); Reescrita da carta de leitor pelos alunos. }\end{array}$ \\
\hline \multicolumn{2}{|r|}{ Etapa 5 - Produção Final (SCHNEUWLY; DOLZ, 2004) } \\
\hline AULA 7 & $\begin{array}{l}3^{\circ} \text { Bilhete Orientador (FUZER, 2012) (Papel de Avaliador); Produção } \\
\text { da versão final das cartas de leitor pelos alunos que serão entregues. }\end{array}$ \\
\hline O Bilhete Orien & $\begin{array}{l}\text { UZER, 2012) no papel de examinador não foi entregue aos alunos para } \\
\text { ins de observação à produção final dos alunos. }\end{array}$ \\
\hline
\end{tabular}

Fonte: os autores, 2018.

\section{Resultados}

Por meio de toda essa contribuição observada, que influenciou consideravelmente esses escritos e a concretização dessa investigação, como o bilhete orientador (COSTA; FUZER, 2011; FUZER, 2012); os indicadores de alfabetização científica (SASSERON; CARVALHO, 2008; PIZARRO; LOPES JÚNIOR, 2015); o modelo de sequência didática observada em (SCHNEUWLY; DOLZ, 2004); as etapas de escrita presente no estudo de Soares (2009 apud COSTA; FUZER, 2011); o modelo de transposição didática (BARROS, 2012) e, por fim, as contribuições teóricas quanto aos conhecimentos de alfabetização científica observados nos trabalhos de (CHASSOT, 2003; LOZENTTI; DELIZOICOV, 2001) que chegamos na proposição desta pesquisa, na qual foi o estabelecer de uma proposta didática interdisciplinar entre Língua Portuguesa e Ciências Naturais.

Para isso organizamos contribuições teóricas e práticas de estudos referenciados e os sistematizamos em uma proposta que buscasse contribuir para as duas disciplinas quanto ao desenvolvimento de habilidades e na observação de indicadores de AC. Quanto aos conteúdos 
próprios de ciências, pautados nas expectativas de aprendizagem para o $5^{\circ}$ ano (Orientações Curriculares do Estado de São Paulo para o Ensino Fundamental nos Anos Iniciais - 2013) e na Matriz de Referência para Avaliação Processual (2016) quanto às habilidades em língua para o segundo semestre do mesmo ano.

\subsection{APRESENTAÇão da SITUAÇão: PRIMEIRA AULA (TERRA E O SISTEMA SOLAR)}

$\mathrm{Na}$ intenção de identificar uma maneira em que a SD envolvendo questões em CTSA poderia iniciar o processo de alfabetização científica nos alunos, direcionamos a análise para a forma como argumentaram e as características expressas que ofereciam indícios desse processo.

Os debates desta aula cercaram a leitura e análise de grupos separados a respeito de fichas técnicas (que também são gêneros textuais), elaboradas previamente e a observação de maquetes. A escolha pelo trabalho com as maquetes exigiu por oportunizar o trabalho com detalhes e características, a fim de que os alunos pudessem correlacionar estas informações e traçarem hipóteses sobre elas. Logo, procuramos por relacionar essa intenção com as expectativas de aprendizagem previstas nas Orientações Curriculares do Estado de São Paulo para os Anos Iniciais (2013) que dizem respeito as características dos planetas.

Nesse planejamento intentou-se instigar os alunos a compreender as informações do texto ficha técnica (delineamento de semelhanças e diferenças). No entanto, apesar desse gênero textual ser sugerido pela Matriz de Referência para a Avaliação Processual (2016) com habilidades previstas para o $2^{\circ}$ ano, foi articulada ao planejamento com a crença de que o trabalho com as fichas possibilitaria maior detalhamento de cada representação.

\subsection{APRESENTAÇ̃̃o DA SITUAÇÃo: SEGUNDA AULA (ASTRONÁUTICA E O LIXO ESPACIAL)}

Nessa segunda intervenção com a turma, procurou-se abordar os conteúdos de História e Filosofia da Ciência e uma problematização em CTSA, a partir do uso de um aspecto sócio científico escolhido previamente - lixo espacial. Buscamos problematizar com os alunos da turma a influência da tecnologia nas descobertas humanas em astronomia (no cotidiano e atualmente) no ambiente, com a temática do lixo espacial.

Desse modo, foi apresentado um vídeo da internet que considerasse critérios como: 1 . História da astronomia; 2. Demonstração da tecnologia como subsídio para as descobertas em astronomia; 3. Evolução da tecnologia dos instrumentos de observação astronômica; 4. Surgimento da ciência astronáutica; 5 . Uso da astronomia no passado e no presente; 6 . Respostas para as principais curiosidades das crianças (buraco negro, tamanho do sol, entre outros). 
Com base na apresentação do vídeo "História da Astronomia" (CUNHA, 2015), retirado da internet, discutiu-se a tecnologia ao longo da evolução da história dessa ciência e suas implicações. Além disso, foi demonstrado imagens de instrumentos de observação, objetos de tecnologia espacial e astronáutica possibilitando a problematização a partir de outro vídeo intitulado "Satélites em Órbita da Terra" (ESPINDOLA, 2011) e as implicações do lixo espacial.

Dessa maneira, após as discussões foram separados grupos designados a representar o discutido num desenho em folha A4. Após o término receberam um caça-palavras elaborado previamente para a busca por palavras chaves implícitas das duas aulas realizadas.

Durante a divisão dos grupos e a realização da atividade proposta de representação das implicações do lixo espacial, alguns dos grupos surpreendentemente apresentaram, por conta própria, além do desenho idealizado, a construção de satélites artificiais, bem como naves e sondas espaciais elaborados por meio de sólidos de papel.

Nessa perspectiva os indicadores de alfabetização científica (SASSERON; CARVALHO, 2008; PIZARRO; LOPES JÚNIOR, 2015) demonstram-se precisamente no percorrer do processo de construção de conhecimento entre os alunos durante as aulas da etapa de apresentação da situação. Como já apontado, esses indicadores são competências e habilidades que podem ser consideradas como próprias da ciência e, consequentemente, do fazer científico. São desenvolvidas e utilizadas para a solução, discussão de situações quando se dá a procura por relações entre o investigado e as construções mentais dos alunos para a compreensão delas.

Expressivamente têm-se o fato de que as realizações dos alunos (argumentações, explicações e hipóteses manifestadas ao decorrer das aulas) talvez não possam ser descritas isoladamente, sem as relacionar com as intervenções feitas pela pesquisa (perguntas elaboradas, exploração dos argumentos dos alunos). Isto posto, consideramos que o realizado pelos alunos e classificado como indicadores de AC, não são concebidos unicamente pelas ações deles, mas consideravelmente pelas condições que oportunizaram tais realizações, isto é, o planejamento de ensino.

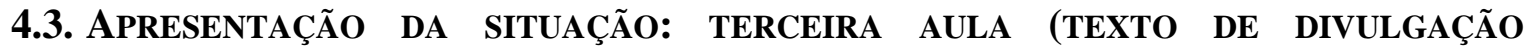 CIENTÍFICA)}

Na sequência desenvolvemos uma atividade com base no gênero textual de divulgação científica, que intentou por observar se os conhecimentos das aulas anteriores seriam subsídios 
para a interpretação desse texto expositivo. Nessa aula especificamente tratamos de um texto exemplo intitulado "Estranhas esponjas amarelas apareceram em uma praia da França" (GALILEU, 2017), a fim de entender as características do texto expositivo de divulgação científica.

Dessa forma, o planejamento da atividade intentou por proporcionar o meio adequado para o desenvolvimento de habilidades que oportunizassem a capacidade de compreensão global de um texto. Sendo assim, a exposição das características do gênero textual expositivo de divulgação científica realizou-se por meio de diálogo, no qual os alunos a partir da leitura do exemplo. Após a leitura houve o tratamento do gênero verbete encontrados por duplas, com a procura de seus significados no dicionário escolar.

Baseado nesses diálogos iniciais foram propostas aos alunos, com base nos descritores de habilidades demonstrados pela Matriz de Referência Para a Avaliação Processual (2016), algumas perguntas para que pudessem responder a partir do texto de divulgação científica: 1 . Qual o assunto do texto? Por quê? - buscar alguma frase que justifique este ser o assunto do texto (tema); 2. Quais as características do objeto encontrado? Esse objeto se parece com alguma coisa? 3. É um texto de divulgação científica? Por quê? (tipologia/estilo).

\subsection{Produção Inicial ou ESCRITA: QUARTA AUla}

A essa etapa de escrita do texto denominamos de produção inicial, pois trata-se de uma redação escrita de uma carta de leitor em resposta ao texto de divulgação científica intitulado "ONU: lixo espacial é ameaça para comunicações na Terra" (TERRA, 2013), sendo baseada também na progressão dos conhecimentos das aulas anteriores. Esta produção visou conhecer o potencial argumentativo dos alunos.

Nessa atividade, os alunos voltaram-se para analisar mais brevemente o texto informativo de divulgação científica. Após a leitura, os alunos começaram a responder as questões propostas: 1. É um texto de divulgação científica? Por quê? (tipologia); 2. Qual o assunto do texto? (tema); 3. Qual a função do texto? (finalidade); 4. O texto divulga uma pesquisa ou comenta um fato em ciência? (finalidade); 5. Qual o meio de publicação deste texto? Internet, revista ou jornal? Por quê? - Explicar com base em qual trecho do texto afirmase o suporte da publicação (suporte); 6. Quem escreveu esse texto? Onde foi publicado? Relacionado a identificação do suporte (situação de produção).

Dessa maneira, aqui começa o acompanhamento do processo de reescrita dos alunos por meio dos bilhetes orientadores (FUZER, 2012; COSTA; FUZER, 2011). Nessa perspectiva, 
apresentamos abaixo um exemplo de produção inicial a fim de exemplificar o processo metodológico discutido na seção anterior.

Quadro 3 - produção inicial de A1

Lixinho

Olá meu nome é C. de C. M. tenho 11 anos sou de ... estou no $5^{\circ}$ ano B da E.

E. Profa. S. V. P. da S. Eu vou dar a minha opinião sobre a publicação postada dia 06/07/13.

Fonte: os autores, 2018.

Quadro 4- primeiro bilhete orientador entregue a A1 (papel de leitor)

Olá, gostei sobre ter lembrado da data do texto. Parabéns!

Não se esqueça de colocar sua opinião e de explicar por que escolheu esse título. Boa sorte!

Fonte: os autores, 2018.

A primeira versão da carta de A1 não apresenta muitas informações e estas, por sua vez, não estão claras, pois apesar de se indicar opinião, ela não foi dada. $\mathrm{O}$ aluno acrescenta um título desconexo, assim como não identifica o assunto. $\mathrm{O}$ primeiro bilhete (entregue na aula 5) apresenta uma observação sobre essa falta de clareza do título e orienta o aluno a continuar explicitando a escolha e demonstrar sua opinião. Tais evidências salientam que, prescindindo das mediações previstas, os repertórios iniciais dos alunos mostram-se distantes das habilidades argumentativas preconizadas.

\subsection{Módulo 1: QUiNTA AUla (REESCRITA ORIENTADA)}

Na realização do Módulo I, a intervenção estava voltada ao gênero carta de leitor. Foram brevemente abordadas as características de estilo da carta de leitor, pois os alunos já tinham conhecimento desse conteúdo.

Com isso, apresentou-se uma carta de leitor de natureza e circulação peculiar em relação as demais de esfera jornalística, sendo esta uma carta de teor político, repleta de palavras de desconhecimento dos alunos. A escolha desse gênero intitulado "Carta em resposta à matéria publicada no jornal Folha de S. Paulo" (MENDES, 2017) não está relacionada a pertinência política ou das manchetes ligadas a política do país. Assim, instituímos-lhes perguntas para que os alunos respondessem: 1. Qual a opinião do autor? Por quê? - buscar alguma frase que justifique esta ser a opinião do autor (opinião); 2. Qual a finalidade desta carta? (finalidade); 3. Qual o argumento do autor ao veículo de informação? (argumentação/contra argumentação). 
Após a leitura do primeiro bilhete orientador, foi iniciada a reescrita das cartas, para a qual foi elaborado um novo bilhete orientador no papel de assistente (entregue na aula 6).

Quadro 5 - segunda versão da carta de leitor de A1

Lixinho Espacial

Olá gente. Bom dia! Meu nome é C. de C. M. tenho 11 sou de ... estou no $5^{\circ} \mathrm{B}$ da profa. L. da escola "E. E. Profa. S. P. V. da S.! Em minha opinião os países tem que tomar medida adequadas para essa situação.

Fonte: os autores, 2018.

Quadro 6 - segundo bilhete orientador entregue a A1 (papel de assistente)

Olá, fico feliz que tenha expressado a sua opinião.

Mas acredito que você possa escrever mais o que você pensa sobre essas medidas adequadas! Será que são todos os países que mandam foguetes e satélites para a órbita da terra? Cuidado com as vírgulas e a pontuação. É importante! Boa sorte!

Fonte: os autores, 2018.

Na segunda versão da carta o aluno informa sua opinião sobre a publicação, porém não cita quem escreveu, o título ou a data de tal publicação. Diferente do primeiro bilhete, a ausência de pontuação é citada na segunda resposta: "Cuidado com as vírgulas e a pontuação. É importante!"

\subsection{Módulo 2: SEXTA AULA (REESCRITA ORIENTADA)}

Nessa atividade procuramos trazer um texto informal, que trouxesse uma problemática próxima da realidade dos alunos. Esse princípio justifica a escolha da carta intitulada "A ciclofaixa de Paes de Linhares" (GROPPO, 2017), publicada pelo Jornal Cruzeiro em julho de 2017.

A carta não discute nenhuma leitura do autor quanto ao jornal. Entretanto, utiliza-se do espaço para questionar modificações em seu município. Essa mudança de finalidade, trouxe aos alunos um novo olhar sobre o objetivo de escrever uma carta de leitor. Além disso, a carta abordada desmistificou o estilo próprio da carta de leitor.

Nesta aula não se fez necessário a busca por verbetes, mas foram respondidas perguntas acerca do texto: 1. Qual a opinião do autor? (opinião); 2. Qual o assunto do texto (tema); 3. É uma carta de leitor? Por quê? (tipologia); 4. A resposta da empresa está correta? Qual a opinião da empresa? - na opinião dos alunos (argumentação/contra argumentação); 5. Esse texto atende 
todas as características da carta de leitor? Sim ou não? Por quê? - justificar quais características (tipologia).

Quadro 7 - terceira versão da carta de leitor de A1

Lixinho Espacial
Olá senhores editores meu nome é C. de C. M. tenho 11 anos moro em ... estudo na
“E.E. profa. S. V.P. da S.” Em minha opinião os países tem que tomar medidas
adequadas para essa situação eles deviam se reunir para "limpar o espaço” ou pelo
menos um pouco e não jogar lixo no espaço com os foguetes, e nós deveríamos fazer
nossa parte né.
Sem mais palavras,
Grata.

Fonte: os autores, 2018.

Quadro 8 - terceiro bilhete orientador entregue a A1 (papel de avaliador)

Olá, seria muito interessante informar onde foi publicada tal notícia, como também a data em que foi publicada na internet. Essas informações são importantes, tanto para os leitores como para o editor do jornal. Procure iniciar os parágrafos colocando a palavra que os inicia um pouco mais à frente.

Não se esqueça da pontuação, isso é fundamental! Boa sorte!

Fonte: os autores, 2018.

Na terceira versão da carta o aluno informa a sua opinião sobre a publicação do texto, porém novamente não cita quem escreveu e qual a data da publicação. $O$ terceiro bilhete (entregue na aula 7) sugere o acréscimo dessa informação.

Durante toda a etapa de pós-escrita, aqui intitulada como módulos, os alunos ressaltaram a importância do bilhete orientador como norteador da reescrita dos textos que produziam. Abaixo algumas das falas dos alunos nos episódios gravados para justificar a afirmação proferida: "Ajuda. Eu inventei um título melhor que combinava com o texto" "É especial o bilhete". "São dicas pra gente, não sei se perceberam, mas são pequenas dicas". Frisamos, com base nas falas transcritas que o bilhete orientador possui essa particularidade para os alunos conforme a produção escrita dos alunos.

\subsection{ProduÇão Final: SÉtima AUla (REESCRITA ORIENTADa)}

A atividade de reescrita orientada para a produção final dos alunos não contou com nenhuma intervenção didática para além dos bilhetes orientadores inseridos nas versões dos 
alunos. Desse modo, os mesmos teriam de analisar a tipologia (estilo, características, suporte) e a finalidade (objetivo, situação de comunicação). Posteriormente a leitura do terceiro bilhete orientador (entregue na aula 7), a turma produziu a última versão de suas cartas de leitor.

Quadro 10 - versão final da carta de leitor de A1

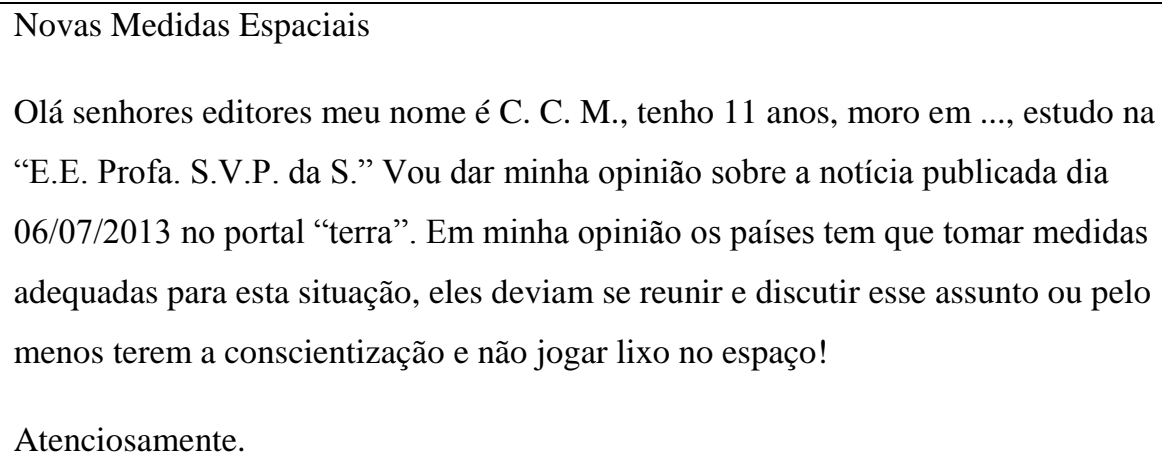

Fonte: os autores, 2018.

Na última versão do texto de $\mathrm{A} 1$, as informações são apresentadas com clareza quanto às anteriores, tudo isso em resposta aos questionamentos realizados nos bilhetes orientadores. $\mathrm{Na}$ última versão do texto, esse aluno também atende ao questionamento presente no primeiro bilhete quanto a sua opinião, informando-a.

Os registros analisados indicam que, a partir da terceira versão, o aluno reflete mais sobre o tema e argumenta, ainda de modo tímido. É por esse motivo que mesmo sem qualquer sugestão presente nos bilhetes orientadores, espontaneamente, modifica seu título.

Em suma, as atividades possibilitaram aos participantes o aprendizado de características próprias dos gêneros textuais citados, assim como, a produção da carta de leitor possibilitou a manifestação verbal de opiniões próprias quanto a um aspecto sócio-científico. Tudo isso, comprovou o potencial argumentativo e crítico-reflexivo da abordagem do enfoque CTSA no ensino de ciências (SANTOS, 2007).

Por meio dos resultados, ainda, pôde-se observar a comprovação da afirmação de Lorenzetti; Delizoicov (2001, p. 3) que nos apresenta o conceito de alfabetizar cientificamente na "capacidade de o indivíduo ler, compreender e expressar opinião sobre assuntos que envolvam a ciência". Essa capacidade foi demonstrada durante o processo de reescrita dos textos e, acreditamos que tenha sido oportunizada pela elaboração do planejamento didático baseado em perspectivas teóricas e instrumentos metodológicos que contextualizam o ensino ao cotidiano, além de objetivos concisos e pautados no desenvolvimento de habilidades. Desse modo, esse estudo permitiu atestar afirmativamente que as ciências naturais podem realmente tornar-se um aperfeiçoador da leitura e escrita nos alunos. No entanto, isto está diretamente 
ligado ao planejamento interdisciplinar com escolhas metodológicas responsáveis pelo professor.

Portanto, os resultados demonstraram a chance de um ensino interdisciplinar contextualizado, não somente em âmbito de junção de conteúdos em pequenos feudos (DEMO, 2001), mas em uma efetiva ligação quanto aos objetivos comuns e a formulação de habilidades que, embora de áreas diferentes, pudessem se auxiliarem contribuindo para o desenvolvimento em um processo comum. Isto caracteriza-se como uma ferramenta eficaz, ativa e essencial para a superação do ensino fragmentado.

\section{CONSIDERAÇões FinaIS}

Consideramos, a partir desta intervenção, que a interdisciplinaridade em ciências pode relacionar-se com outras áreas específicas do currículo escolar, no intuito de promover interações entre o aluno, professor e o dia a dia, visto que atualmente a ciência e o avanço tecnológico têm se expandido no cotidiano, gerando reflexões para o ensino de CTSA e sua finalidade. $\mathrm{O}$ conceito de interdisciplinaridade não surgiu a fim de diluir as disciplinas no ambiente escolar, pelo contrário, ainda mantém particularidades. Contudo, integra as mesmas com seus conteúdos, baseado na compreensão dos múltiplos fatores que intervêm sobre a realidade, abrangendo diversas linguagens que são necessárias para o conhecimento dos alunos.

A interdisciplinaridade não pode ser concebida unicamente como uma junção de conteúdos, métodos ou disciplinas. Mas a implicação de um pensar e agir que oportunizam a interatividade mediada pelo professor de conhecimentos e situações diversificadas. Essa é uma procura pela superação da linearidade do currículo, em uma reorganização de uma nova prática curricular, produzindo uma nova situação em que conhecimentos de ciência participam com o cotidiano fora da escola.

Advoga-se que a abordagem de aspectos sócio-científicos (ASC) pode contribuir à problematização das aulas. Essa abordagem é uma forma de problematização ao currículo, visto que implica em refletir no porquê e para quê ensinar ciências, com finalidade de reflexão sobre problemáticas do cotidiano, o que, por sua vez, ultrapassa o ensino de ciências como conteúdos curriculares previamente estabelecidos.

\section{REFERÊNCIAS}

BARROS, E. M. D. de. Transposição didática externa: a modelização do gênero na pesquisa colaborativa. Raído, Dourados, v. 6, n. 11, p. 11-35, 2012. Disponível em:

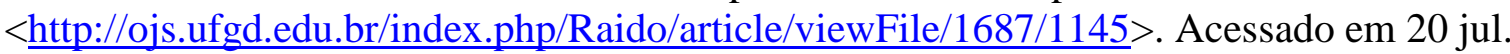
2017. 
BRONCKART, J. P. Atividade de linguagem, textos e discursos: por um interacionismo sócio-discursivo. São Paulo: EDUC, 2003.

BRASIL. Secretaria de Educação Fundamental. Parâmetros curriculares nacionais: ciências naturais. Brasília: MEC/SEF, 1997. Disponível em:

<http://portal.mec.gov.br/seb/arquivos/pdf/livro04.pdf>. Acessado em 24 fev. 2017.

CHASSOT, A. Alfabetização científica: uma possibilidade para a inclusão social. Revista Brasileira de Educação, Rio de Janeiro: ANPED, v. 8 n. 22. p. 89-100, 2002. Disponível em: $<$ http://www.scielo.br/pdf/rbedu/n22/n22a09.pdf $>$. Acessado em 10 fev. 2017.

COSTA, F. B. da; FUZER, C. Processo de ensino de produção textual no ensino básico: um relato de experiência. Artigo apresentado ao curso de Letras - Português e Literaturas EAD, da Universidade Federal de Santa Maria (UFSM - RS), 2011. Disponível em: $<$ http://jararaca.ufsm.br/websites/1\%26c/download/Artigos12/cris_fabiano.pdf.pdf >. Acessado em: 16 jun. 2017.

CUNHA, F. História da astronomia. YouTube. 22 jul. 2015. Disponível em: <https://www.youtube.com/watch?v=mcfV5vblyRM>. Acessado em 20 jul. 2017.

DEMO, Pedro. Professor/Conhecimento. UnB, 2001. Disponível em: 〈http://antigo.enap.gov.br/downloads/ec43ea4fProfessor_Conhecimento.pdf $>$. Acessado em: 16 ago. 2017.

ESPINDOLA, E. Satélites em órbita da terra. YouTube. 26 jul. 2011. Disponível em: <https://www.youtube.com/watch?v=42amqKU2Hjo >. Acessado em 20 jul. 2017.

FUZER, C. Bilhete orientador como instrumento de interação no processo ensinoaprendizagem de produção textual. Letras, Santa Maria, v. 22, n. 44, p. 213-245, 2012. Disponível em: < https://periodicos.ufsm.br/letras/article/view/12198/0>. Acessado em 15 ago. 2017.

GALILEU (Revista). Estranhas esponjas amarelas apareceram em uma praia da França. Revista Galileu, 2017. Disponível em: $<$ http://revistagalileu.globo.com/Ciencia/noticia/2017/07/estranhas-esponjasamarelasapareceram-em-uma-praia-da-franca.html>. Acessado em: 30 jul. 2017.

GROPPO, D. D. Ciclofaixa paes de linhares. Disponível em: <http://www.jornalcruzeiro.com.br/materia/805520/do-leitor $>$. Acessado em 24 jul. 2017.

LORENZETTI, L.; DELIZOICOV, D. Alfabetização científica no contexto das séries iniciais. ENSAIO - Pesquisa em Educação em Ciências, v. 3. n.1, p. 45-61, 2001. Disponível em: $<$ http://www.scielo.br/pdf/epec/v3n1/1983-2117-epec-3-01-00045.pdf $>$. Acessado em 22 fev. 2017.

MENDES, G. Carta em resposta à matéria publicada no jornal Folha de S. Paulo. Disponível em: <http://www.tse.jus.br/imprensa/noticias-tse/2017/Abril/carta-em-respostaamateria-publicada-no-jornal-folha-de-s-paulo-1>. Acessado em 08 ago. 2017.

MORAIS, M. B.; ANDRADE, M. H. de P. Ciências - ensinar e aprender. Belo Horizonte: Dimensão, 2009. 
PETRONILO, A. P. da S. Dificuldade de aprendizagem na leitura e na escrita. Brasília, 2007. 54 p. Monografia (Especialização) - Universidade de Brasília. Centro de Ensino a Distância, 2007.

PIZARRO, M. V.; LOPES JÚNIOR, J. Indicadores de alfabetização científica: uma revisão bibliográfica sobre as diferentes habilidades que podem ser promovidas no ensino de ciências nos anos iniciais. Investigações em Ensino de Ciências, v. 20. n. 1, p. 208-238, 2015. Disponível em: <https://www.if.ufrgs.br/cref/ojs/index.php/ienci/article/view/66 > Acessado em 23 jul. 2017.

SANTOS, W. L. P. dos. Educação científica na perspectiva de letramento como prática social: funções, princípios e desafios. Revista Brasileira de Educação, v. 12. n. 36, p. 474-550, 2007. Disponível em: $<$ http://www.scielo.br/pdf/rbedu/v12n36/a07v1236.pdf $>$. Acessado em 18 jun. 2017.

SÃO PAULO. Secretaria Estadual da Educação. Matriz de avaliação processual: anos iniciais, língua portuguesa e matemática; encarte do professor. São Paulo: SEE, 2016. Disponível em: <https://drive.google.com/file/d/0ByQnM4HSIaBuTFF2eDlKWm8yYlU/view>. Acessado em 26 mai. 2017.

SÃO PAULO. Secretaria Estadual da Educação. Orientações curriculares do Estado de São Paulo: ciências da natureza, ciências humanas: geografia e história, versão preliminar ensino fundamental anos iniciais. São Paulo: CGEB, 2013. Disponível em: <http://www.cdcc.usp.br/cda/PARAMETROS-CURRICULARES/Sao-Paulo-FazEscola/Ciclo-I/orientacoes_estado_cie_his_geo.pdf>. Acessado em 25 mai. 2017.

SASSERON, L. H.; CARVALHO, A. M. P. de. Almejando a alfabetização científica no ensino fundamental: a proposição e a procura de indicadores do processo. Investigações em Ensino de Ciências. v. 13. n. 3, p. 333-352, 2008. Disponível em: $<$ https://www.if.ufrgs.br/cref/ojs/index.php/ienci/article/view/445/263 $>$. Acessado em 23 jul. 2017.

SCHNEUWLY, B.; DOLZ, J. Gêneros orais e escritos na escola. Campinas: Mercado de Letras, 2004.

TERRA (Portal). ONU: lixo espacial é ameaça para comunicações na terra. Disponível em: $<$ https://www.terra.com.br/noticias/ciencia/espaco/onu-lixo-espacial-e-ameaca-paracomunicacoes-na-terra,22a2414baaaaf310VgnCLD2000000dc6eb0aRCRD.html> . Acessado em 20 jul. 2017.

VIECHENESKI, J. P.; CARLETTO, M. R. Ensino de ciências e alfabetização científica nos anos iniciais do ensino fundamental: um olhar sobre as escolas públicas de Carambeí. In:

ENCONTRO NACIONAL DE PESQUISA EM EDUCAÇÃ̃O EM CIÊNCIAS (ENPEC), 8, 2011, Campinas: UNICAMP, 2011. p. 1-12. Disponível

em: $<$ http://www.nutes.ufrj.br/abrapec/viiienpec/resumos/R0741-1.pdf $>$. Acessado em: 16 fev. 2017.

Recebido em: 15 de outubro de 2018

Aprovado em: 19 de dezembro de 2018. 